Old Dominion University

ODU Digital Commons

Nursing Faculty Publications

Nursing

2017

\title{
Holistic Self-Care: Tai Chi, Qigong Training for Caregivers at an Alzheimer Disease Assisted Living Facility
}

Sunny Alperson

Old Dominion University, salperso@odu.edu

Christianne Fowler

Old Dominion University

Follow this and additional works at: https://digitalcommons.odu.edu/nursing_fac_pubs

Part of the Geriatric Nursing Commons

Original Publication Citation

Alperson, S., \& Fowler, C. (2017). Holistic self-care: Tai chi, qigong training for caregivers at an alzheimer disease assisted living facility. Annals of Long-Term Care, 25(5), 33-38. doi:10.25270/altc.2017.10.00003

This Article is brought to you for free and open access by the Nursing at ODU Digital Commons. It has been accepted for inclusion in Nursing Faculty Publications by an authorized administrator of ODU Digital Commons. For more information, please contact digitalcommons@odu.edu. 


\section{Holistic Self-Care: Tai Chi, Qigong Training for Caregivers at an Alzheimer Disease Assisted Living Facility}

Sunny Alperson, PhD, FNP-BC • Christianne Fowler, DNP, GNP-BC

\author{
Affiliation: \\ Old Dominion University, Norfolk, VA

\section{Disclosures:} \\ The Old Dominion University Research \\ Foundation, Summer Research Fellowship \\ Program provided a faculty stipend and \\ some funding for research expenses.
}

\section{Acknowledgments:}

Thanks to Jay Alperson, PhD, who assisted with Qualtrics Software, SPSS, and data analyses.

Address correspondence to:

Sunny Alperson, PhD, FNP-BC

College of Health Sciences

Old Dominion University

4608 Hampton Blvd

Norfolk, VA 23529

Office: (757) 683-5256

Fax: (757) 683-5253

Email: salperso@odu.edu

\begin{abstract}
With the growing number of older persons with chronic illnesses, the demand for professionals who can provide complex care is increasing as well. However, evidence shows that health professionals' burnout rate has been consistently increasing for the last 3 decades. In an effort to alleviate some of the issues associated with caregiver burnout, we conducted mind-body training of self-compassion for professional caregivers at an Alzheimer disease (AD) specialty center for 5 weeks. The intervention combined seven simple centering movements of tai chi and qigong in a context of mettā (loving kindness meditation) language mindfulness. Data showed significant improvements in caregiver Mindful Self Compassion, Psychological Social Well-being, General Self-Efficacy, and Positive and Negative Experience scales. In the context of improving health care delivery, the understanding that offering loving kindness to oneself increases compassion for others has significant implications, as it intertwines personal and professional development together. A research trajectory for future studies is suggested, which may lead to a practical self-care intervention for health care professionals.
\end{abstract}

Key words: mindfulness, caregiver, self-compassion, meditation, tai chi, qigong Citation: Ann Longterm Care. 2017;25(5):33-38.

DOI: 10.25270/altc.2017.10.00003

Received December 13, 2016.

Accepted April 10, 2017. 
in environment, positive caregiver attitudes, and calming approaches during interactions. Finding innovative alternative approaches, which can increase caregivers' compassion toward the person with dementia while also improving caregivers' own self-care, are needed. Improving the culture of the care environment is an area of research currently requiring more investigation. ${ }^{2,3,7-9}$

Changes can come to the nation's health care when the consciousness of care providers changes. As the Institute of Medicine stated in its 2009 position statement, ${ }^{10}$ health care needs to break out of an extreme dependence on biomedical modalities of pills and technology and move toward more integrative, comprehensive, whole-person care approaches in research, education, and clinical practice. With increasing prevalence of older persons and of chronic illnesses, the demand for professionals who can provide complex care increases. Yet, evidence shows that health professionals' burnout rate has been consistently increasing for the last 3 decades, which also coincides with the loss of public trust in health care providers. ${ }^{10}$ It is urgent to establish care routines for those who take care of others in order to tackle the chronic disease crises with which we are faced.

Mindfulness, a mind cultivation psychology and philosophy of Buddhist origin, is defined as "the non-judgmental awareness of what is happening in the present moment"11 or as a practice toward a state of mind unburdened by cluttered thought processes, leading to profound awareness of the present moment as is. ${ }^{12}$ Since the 1970 s, mindfulness has been secularized and has evolved into many versions of intervention research in health care. These mindfulness interventions, in-motion or sitting still, are collectively termed mindfulness-based interventions (MBI), which includes mindfulness-based stress reduction ${ }^{11}$ and mindfulness-based cognitive therapy. ${ }^{13}$

MBI research has grown in recent years. Evidence of its efficacy has increased, supported by clinical and basic research studies in neurocognitive science, psycho-immunology, and neuroplasticity, which have demonstrated brain activity changes after mindfulness mediation. ${ }^{14}$ The most recent derivative of $\mathrm{MBI}$ is mindfulness-based self-compassion. While self-compassion studies have been around for decades, Germer and Neff have recently synthesized mindfulness and self-compassion into a successful hybrid called mindful self-compassion (MSC). ${ }^{15-18}$ In order to offer meaningful kindness to oneself, a sense of self-awareness and insight into oneself is required, which all mindfulnessrelated practices foster. Although there are subtle differences in technical developments of different mindfulness-based meditations, a common denominator is to focus attention on something - whether that is on breaths, a concept, a phenomenon, on words of meditation, on sensory exploration, or with open-field awareness of the surrounding environment. All Buddhist meditation practice involves redirecting and focusing attention upon what one wishes to focus. The fundamental metaphysics of Buddhist meditation revolves around understanding the nature of "self," ultimately leading to a state of self-cancellation of "selflessness." A Buddhist practitioner may say that when one understands oneself better, one does not have a choice but to be compassionate to others; this is to say that self-compassion is synonymous with humility if practiced mindfully. ${ }^{19,20}$ Thus, MSC may be thought of as a natural way to develop deeper compassion for others by understanding the interconnectedness of all humanity.

MSC specifically utilizes maitri or mettā, which are Pali words often translated as "loving-kindness meditation" (LKM) in Western culture (Pali is a Prakrit language native to the Indian subcontinent). The object of focus in LKM is on language. Mettā is the first of four intricately interconnected components. Practitioners can focus attention on the meaning of mett $\bar{a}$ words by chanting words that evoke easiness and peaceful feelings along with hopeful positive messages of life. Such phrases like "May I and all beings be free from suffering and be at peace"; "May I care for myself with ease"; "May I love and be loved," are some examples. ${ }^{15}$ The other three aspects are compassion (kaeruna: the ability to ease pain), joy (mudita: true love brings joy), and freedom (upeksha: when you love, you bring freedom to the person you love). The fundamental Buddhist assumption of LKM is the training of the mind for radical acceptance and kindness to all beings including self. ${ }^{21}$ Thich Nhat Hanh offers an explanation of this aspect of Buddhist philosophy under the heading "The Four Aspects of Love" in the book True Love, providing more specifics about what is entailed in LKM. ${ }^{22}$

A large body of evidence has also shown tai chi (TC) an ancient Chinese martial art system that has evolved into a gentle health and wellness exercise-to be a comprehensive health care modality in clinical variables for illness treatment, health prevention, and rehabilitation. As a moderate aerobic physical exercise, TC provides general health benefits across many body systems. ${ }^{23}$ Moreover, robust evidence $e^{24,25}$ has shown TC to be an effective fallprevention tool for the aging populations; and various kinesiology-related studies of posture and gait in the laboratory are ongoing. The most recent review of 107 systematic reviews of TC in 2016 identified positive effects on hypertension, cognitive performance, arthritis, depression, pain, falls, balance and strength, and chronic obstructive pulmonary disease. ${ }^{24}$ Qigong, also of Chinese origin and in the martial arts realm, is an umbrella term that includes activities such as breaths, mindfulness, and mindful movements for health, well-being, and healing practice. Both TC and qigong have ancient roots as nonpharmacological healing modalities. For example, one record shows that the movement system of qigong, "Five Animal Frolics" was 
used around $220 \mathrm{AD}$ by a physician, Hua Tuo, for the purpose of improving health of the public and to increase cure rate of his patients. ${ }^{26}$

This study sought to evaluate the effectiveness of MSC training for caregivers over a 5-week period using a combined approach of LKM language with seven centering movements hybridized from TC and qigong (ie, TCQ movements).

The immediate objective of this study was to investigate the efficacy of the mind-body-spiritual training on AD caregivers in an assisted living facility (ALF). The broader clinical goal is to develop an evidence-based, holistic selfcare tool based on a nonreductionist model that can ultimately be used as a means to effectuate a compassionate culture of healing and caregiving among individuals caring for adults with BSD, which can, by extension, improve care for older adults.

\section{Methods \\ Participants and Study Design}

The design of this intervention was first successfully pilot tested for feasibility 10 months prior at an urban university with advanced nursing professionals enrolled in a doctor of nursing practice program. The consequent study and intervention detailed here were approved by Old Dominion University institutional review board.

Study participants were caregivers at an ALF specializing in the care of individuals with $\mathrm{AD}$ and other dementias. With administrator's permission, research flyers were posted on the facility's bulletin board announcing date of an orientation and subsequent Q\&A sessions related to the proposed intervention. Informed consent was explained at each orientation session by the researchers, and total of 34 interested volunteers signed the informed consent forms.

The intervention was conducted during August and September of 2016 (2 weeks after participant orientation) and consisted of 5 weekly workshops offered as in-service education (continuing education) for 1 hour, with all sessions conducted at the facility "theater room." The training focused on interactive and integrative teaching of MSC and LKM along with seven simple TCQ moves to reinforce the self-healing concept. A holistic approach was taken with emphasis on acquiring simple skills likely to foster better patient care simultaneously with self-compassion development in the caregivers.

Pre- and post-surveys, made up of the same questions/ scales, were given to participants before and after the training period to determine any changes among individual caregivers. Participation was voluntary and confidential with all collected data de-identified and withheld from facility administrators and fellow participants. The caregivers were free to withdraw at any time during the proceedings. Each participant received a small compensation for completing all study questionnaires. The surveys were administered via Qualtrics software using facility computers.

\section{Outcome Measures}

This study used a single-group, repeated-measures design with a nonprobability convenience sample of participants. The primary dependent variables were well-validated measures surveying the caregivers' self-compassion, spirituality, work stresses and relationships, positive and negative experiences, psychological and social well-being, and general self-efficacy. ${ }^{27,28}$

The first dependent measure was the Self-Compassion Scale-Short Form (SCS-SF) ${ }^{29}$ It consists of 12 items with ratings on a 5-point scale. A sample item is "When something painful happens, I try to take a balanced view of the situation."

The second dependent measure was the Spirituality Perspective Scale (SPS). ${ }^{30}$ It had 10 items with ratings running from 1 to 6 . A sample item is "Forgiveness is an important part of my spirituality."

The next dependent measure, the Professional Care Team Burden Scale (PCTB), was targeted to assess stress on caregivers for dementia patients. ${ }^{31}$ This scale had 10 items with ratings on a 5-point scale. A sample item is "My work performance is respected by my colleagues."

The fourth measure, the Scale of Positive and Negative Experience (SPANE) assessed subjective feelings of wellbeing and ill-being. ${ }^{32-34}$ It consists of 6 positive feelings (SPANE-P) and 6 negative feelings (SPANE-N); respondents rated how often the feelings occur on a scale of 1 to 5 . Sample feelings are "happy" and "sad."

The fifth measure, the Psychological and Social Well Being Scale (PWB; also known as the Flourishing Scale) is designed to measure social-psychological prosperity. ${ }^{32}$ It consists of eight statements describing the participant; ratings are obtained on a 7-point scale ranging from strongly disagree to strongly agree.

The last primary measure, General Self-Efficacy (GSE) ${ }^{35}$ has higher scores associated with less depression, less perceived pain, better health, and better life satisfaction. It consists of 10 items rated on a 4-point scale. A sample item is "I can solve most problems if I invest the necessary effort."

\section{Data Analysis}

Data analysis was conducted with SPSS 21.0 (IBM). Repeated measure analyses were performed with the pre- and post-scores from the surveys. All inferential tests were paired $t$ tests, 2 -tailed.

\section{Results}

Demographic results were obtained from 34 volunteers (all female) for the study: 19 caregivers (55.9\%) completed both pre- and post-surveys of the intervention. Of these 19 participants, the mean age was 38 years, with a standard deviation 
of 13 years. Of all participants, $63 \%$ were ethnically NonHispanic $(n=12), 11 \%$ were ethnically Hispanic $(n=2)$, and $26 \%$ had unknown/undeclared ethnicity $(n=5)$. Their racial backgrounds were diverse, with $43 \%$ white $(n=10)$, $22 \%$ Asian $(\mathrm{n}=5), 13 \%$ racially Hispanic $(\mathrm{n}=3), 9 \%$ black $(n=2)$, and $13 \%$ other $(n=3)$. The frequencies total more than 19 because some participants marked more than one racial background. The mean experience of caregivers working with $\mathrm{AD}$ patients was 8.5 years with a standard deviation of 3.3 years. In terms of educational background, $58 \%$ of participants $(n=11)$ had a high school or 2-year college associate of art degree, and 42\% ( $n=8)$ had a higher degree.

All pre-post differences were in the hypothesized direction of improvement, as shown in Table 1, which contains the means, standard deviations, and paired $t$ values for all survey variables. Inferential repeated measure tests revealed significant improvements as demonstrated through the SCS $\left(t_{18}=3.75, \mathrm{P}<.01 ;\right)$, SPANE-P $\left(t_{18}=4.22, P<.01\right)$ and SPANE-N $\left(t_{18}=-3.29, P<.01\right)$. These results suggested participants' feelings of self-compassion and positive experiences significantly increased while negative experiences significantly decreased after the intervention. Their psychological well-being and their feelings of general self-efficacy increased significantly following the intervention (PWB $\left(t_{18}\right.$ $=3.14, P<.01$ ), and (GSE: $\left.t_{18}=2.54, P<.02\right)$. Thus, improvements in compassion, positive and negative experience, psychological and social well-being, and general self-efficacy were consistent in the caregivers, as illustrated in their $t$ tests.

Two dependent variables did not change significantly. The changes in professional care team burden and spirituality perspective failed to reach significance (PCTB: $t_{18}=-0.57$, $P>.05$; SPS: $t_{18}=1.54, P>.05$.).

\section{Discussion}

This was an exploratory study of a combined intervention using MSC with seven TCQ movements and LKM language for professional caregivers in a dementia care facility. The clinical goal was to provide an easy-to-learn, mind-body spiritual intervention that can be used for self-care for these caregivers. Based on the measures used in pre- and post-surveys, caregivers showed improved feelings of self-compassion, well-being, self-efficacy, and positive experience after receiving self-healing training. To the authors' knowledge, it is the first attempt to quantitatively assess the impact of MBI that combines body movement and language mindfulness to train individuals in MSC. This current study is the first testing of the intervention in a clinical facility setting.

A combined intervention of LKM language and body mindfulness using TCQ is an easy, cost-effective, portable strategy that can be practiced anywhere. Unlike other specialties such as psychotherapy, it does not require specialized training. Instead, it consists of basic centering movements (body-mindfulness) and words to repeat in silence like a mantra (LKM), setting the tone and context of self-compassion training. The advantage of the combined strategy is the engagement of the whole person paradigm-body-mindspirit healing - which aims to enhance the internal absorption of compassion and self-compassion.

Taken as a whole, the change in dependent variables was consistent with improved self-care of the caregivers following the 5 weeks of training in MSC using LKM and TCQ. These results are consistent with past studies on beneficial effects of MSC, TC, and qigong spanning a variety of treated populations. ${ }^{11,13-18,21,23-27,29,30,36-43 \text {, }}$

The seven simple TCQ centering moves selected for this study were deemed to be easy for caregivers to teach patients (information on specific moves used are available upon request). They can be taught while patients are in sitting, lying, or standing positions. These movements can be used to develop a common language between the patients and the caregivers, serving as gestures and symbols to calm the patients' emotion or as signals to embrace themselves.

Some intriguing occurrences worthy of reporting were that several patients repeatedly stood outside the window looking in while their caregivers were performing selfcompassion TCQ; this happened consistently during the 5 weeks. Staff told the researchers of the patients' great curiosity, and they experimented with the techniques in their recreational program activities; this was unexpected. The staff taught easy movements to the patients from week 3 . What was evident to the researchers was the sincere enthusiasm expressed by staff when they discovered that good selfcare, compassion, and kindness to self could result in better, more compassionate care for the patients.

From the health care professional's perspective, the understanding that offering loving kindness to oneself increases compassion for others has significant implications, precisely because it intertwines personal and professional development together. For those who practice self-compassion and kindness, the benefits extend beyond just oneself. LKM practice can change the level of compassion and attitude toward others subsequently following with a different interactional frame of feelings and mindset, as described in a number of studies. ${ }^{15,19,38}$ For example, a frustrated participant from one of the studies who frequently lost her temper from caring for her sick, older mother stated the changes after LKM: "When I enter her room now, I can feel myself soften." A business man also pondered, "I never knew it was possible to have such space in my heart for other." 15

The hybridized movements of TCQ have been getting increased recognition as phenomena with benefits beyond just physical. They are moving meditations that share the same philosophical foundations of viewing humans as whole mind-body-spiritual complexes rather than reducible entities separable into body or mind. ${ }^{39-41}$ One recent comprehensive review of health benefits of TCQ studies 


\begin{tabular}{|c|c|c|c|c|c|}
\hline Variable & $\begin{array}{l}\text { Time } \\
\text { Period }\end{array}$ & Mean & $\begin{array}{l}\text { Standard } \\
\text { Deviation }\end{array}$ & $t$ values & $\begin{array}{l}P \text { value } \\
\text { (2-tailed) }\end{array}$ \\
\hline \multirow{2}{*}{ Self-Compassion Scale ${ }^{a}$} & $\begin{array}{l}\text { Post } \\
\text { Pre }\end{array}$ & $\begin{array}{l}3.58 \\
3.04\end{array}$ & $\begin{array}{l}0.69 \\
0.69\end{array}$ & & \\
\hline & Post-Pre & 0.54 & 0.63 & 3.75 & .001 \\
\hline \multirow{2}{*}{$\begin{array}{l}\text { Spirituality Perspective } \\
\text { Scale }\end{array}$} & $\begin{array}{l}\text { Post } \\
\text { Pre }\end{array}$ & $\begin{array}{l}4.08 \\
3.73\end{array}$ & $\begin{array}{l}1.58 \\
1.47\end{array}$ & & \\
\hline & Post-Pre & 0.35 & 1 & 1.54 & .141 \\
\hline \multirow{2}{*}{$\begin{array}{l}\text { Professional Care Team } \\
\text { Burden }\end{array}$} & $\begin{array}{l}\text { Post } \\
\text { Pre }\end{array}$ & $\begin{array}{l}9.89 \\
10.63\end{array}$ & $\begin{array}{l}5.83 \\
5.06\end{array}$ & & \\
\hline & Post-Pre & -0.74 & 5.67 & -0.57 & .578 \\
\hline \multirow{2}{*}{$\begin{array}{l}\text { Scale of Positive and Negative } \\
\text { Experience - Positive }^{a}\end{array}$} & $\begin{array}{l}\text { Post } \\
\text { Pre }\end{array}$ & $\begin{array}{l}25.58 \\
22.63\end{array}$ & $\begin{array}{l}3.36 \\
3.76\end{array}$ & & \\
\hline & Post-Pre & 2.95 & 3.05 & 4.22 & .001 \\
\hline \multirow{2}{*}{$\begin{array}{l}\text { Scale of Positive and Negative } \\
\text { Experience - Negative }^{a}\end{array}$} & $\begin{array}{l}\text { Post } \\
\text { Pre }\end{array}$ & $\begin{array}{l}13.05 \\
16.11\end{array}$ & $\begin{array}{l}3.06 \\
4.14\end{array}$ & & \\
\hline & Post-Pre & -3.05 & 4.05 & -3.29 & .004 \\
\hline \multirow{2}{*}{$\begin{array}{l}\text { Psychological and Social Well } \\
\text { Beinga }\end{array}$} & $\begin{array}{l}\text { Post } \\
\text { Pre }\end{array}$ & $\begin{array}{l}37.37 \\
34.58\end{array}$ & $\begin{array}{l}2.31 \\
2.99\end{array}$ & & \\
\hline & Post-Pre & 2.79 & 3.87 & 3.14 & .006 \\
\hline \multirow{2}{*}{ General Self Efficacya } & $\begin{array}{l}\text { Post } \\
\text { Pre }\end{array}$ & $\begin{array}{l}34.11 \\
32.37\end{array}$ & $\begin{array}{l}4.15 \\
4.34\end{array}$ & & \\
\hline & Post-Pre & 1.74 & 2.98 & 2.54 & .02 \\
\hline
\end{tabular}

aStatistically significant at the $P<.05$ level; degrees of freedom $=18$.

reported improvements on psychiatric symptoms such as anxiety and depression, in addition to general benefits in bone density, cardiopulmonary conditions, and improvements in physical function, balance, fall prevention, quality of life, and self-efficacy. ${ }^{23}$ Patients with progressive illnesses like Parkinson disease who practiced simplified TC interventions showed significant improvements in postural control and mobility speed while also showing gains in desire to continue TC activity as compared to desire to continue in other forms of exercise. ${ }^{25,42,43}$

LKM and MSC researchers conclude that even very short periods of mettā meditation can change brain activities and increase compassion towards themselves and others. LKM significantly increases positive emotions in the participants such as joy, love, gratitude, hope, amusement, and awe. ${ }^{36}$ For example, in one online practice of LKM for 30 minutes a day for 2 weeks compared with a group that learned to "cognitively reappraise" their life situation, only the mettā group showed increases in activity of the insula via functional magnetic resonance imaging, the brain region of empathy highly correlated with well-being and self-compassion. ${ }^{37,44}$

There were limitations in this study that could be addressed in future research. The lack of a control group to examine demand effects, the lack of follow-up assessment, the omission of power analysis to size the sample for significance tests, and the lack of a components analysis all could be remedied in further studies. All the dependent variables deserve more and longer investigation via replication. With 
more replications of this intervention with larger and different populations, and with better controlled experimental designs, there may be an opportunity to demonstrate and significantly improve professionals' self-care. We are currently proposing a randomized controlled study using a multisite design.

During this study, we did hold a secondary exploratory hypothesis that addressed changes in patient behaviors. Secondary variables were taken from the recordings of a sample of $\mathrm{AD}$ patients at the facility. These variables were taken from aggregated patient data, which were routinely updated by medical students on all patients, enabling researchers to investigate possible changes compared 1 month prior and 1 month following the self-compassion training. Data included increase or decrease in overall behavioral medication use and other behavioral indicators such as frequencies of incident reports. The results will be reported in a separate publication.

\section{Conclusion}

Mind-body-spiritual training of caregivers with self-compassion TCQ and LKM can offer a holistic, nonpharmacological approach to better self-care for caregivers and, ideally, better care for the older adults they care for. Clinicians can learn to care for themselves via continuing education; they can then teach their patients, thus meeting both personal and professional agenda of a mutual healing effort. Finding "the healer within" is not a new concept, but it remains only a concept or ideal for most health care delivery systems. Following more validation via replications and randomized trials, mind-body self-compassion with TCQ can serve as a personal and professional practice as well as a practical bridge to a reality of more compassionate health care.

\section{References}

1. Alzheimer's Association. 2017 Alzheime's disease facts and figures. http://alz.org/ documents_custom/2017-facts-and-figures.pdf. Accessed August 21, 2017.

2. Kales HC, Gitlin LN, Lyketsos CG. Assessment and management of behavioral and psychological symptoms of dementia. BMJ. 2015;350:h369.

3. Brodaty H, Connors MH, Xu J, Woodward M, Ames D, PRIME study group. Predictors of institutionalization in dementia: a three year longitudinal study. $J$ Alzheimers Dis. 2014;40(1):221-226.

4. de Vugt ME, Stevens F, Aalten P, Lousberg R, Jaspers N, Verhey FR. A prospective study of the effects of behavioral symptoms on the institutionalization of patients with dementia. Int Psychogeriatr. 2005;17(4):577-589.

5. Aboulafia-Brakha T, Suchecki D, Gouveia-Paulino F, Nitrini R, Ptak R. Cognitivebehavioural group therapy improves a psychophysiological marker of stress in caregivers of patients with Alzheimer's disease. Aging Ment Health. 2014;18(6):801-808.

6. Cohen-Mansfield J, Juravel-Jaffe A, Cohen A, Rasooly I, Golander H. Physicians' practice and familiarity with treatment for agitation associated with dementia in Israeli nursing homes. Int Psychogeriatr. 2013;25(2):236-244.

7. Molinari V, Chiriboga D, Branch LG, et al. Provision of psychopharmacological services in nursing homes. J Gerontol B Psychol Sci Soc Sci. 2010;65B(1):57-60.

8. Gaugler JE, Wall MM, Kane RL, et al. The effects of incident and persistent behavioral problems on change in caregiver burden and nursing home admission of persons with dementia. Med Care. 2010;48(10):875-883.

9. Pinquart M, Sörensen S. Gender differences in caregiver stressors, social resources, and health: an updated meta-analysis. J Gerontol B Psychol Sci Soc Sci. 2006;61(1):P33-P45.

10. Institute of Medicine. Integrative Medicine and the Health of the Public: A Summary of the February 2009 Summit. Washington DC: The National Academies Press; 2009.
11. Kabat-Zinn J. Bringing mindfulness to medicine. Altern Ther Health Med. 2005;11(3):56-64.

12. Loori JD. The Art of Just Sitting; Essential Writings on the Zen Practice of Shikantaza, 2nd ed. Boston, MA: Wisdom Publication; 2004.

13. Leahey $\mathrm{T}$, Crowther J, Irwin S. A cognitive-behavioral mindfulness group therapy intervention for the treatment of binge eating in bariatric surgery patients. Cognitive Behav Pract. 2008;15(4):364-375.

14. Lutz A, Brefczynski-Lewis J, Johnstone T, Davidson RJ. Regulation of the neural circuitry of emotion by compassion meditation: effects of meditative expertise. PLOS One. 2008;3(3):e1897.

15. Germer CK. The Mindful Path to Self-Compassion. New York, NY: Guilford Press; 2009.

16. Germer CK, Neff KD. Self-compassion in clinical practice. J Clin Psychol. 2013;69(8):856-867.

17. Neff KD. Self compassion and psychological well-being. Constructivism in the Human Sciences. 2004;9(2):27-37.

18. Neff KD. Development and validation of a scale to measure self-compassion. Self and ldentity. 2003;2:223-250.

19. Hahn T. The Heart of the Buddha's Teaching: Transforming Suffering into Peace, Joy and Liberation. New York, NY: Broadway Books; 1998.

20. Weil S. Late Philosophical Writings. Notre Dame, IN: Notre Dame Press; 1998.

21. Salzberg S. Lovingkindness: The Revolutionary Art of Happiness. Boston, MA: Shambhala; 1995.

22. Hanh T. True Love: A Practice for Awakening the Heart. Kohn SC, trans. Boston, MA: Shambhala, 2011. https://terebess.hu/zen/mesterek/Thich\%20Nhat\%2OHanh\%20 -\%20True\%20Love.pdf. Accessed September 11, 2017.

23. Jahnke R, Larkey L, Rogers C, Etnier J, Lin F. A comprehensive review of health benefits of qigong and tai chi. Am J Health Promot. 2010;24(6):e1-e25.

24. Solloway MR, Taylor SL, Shekelle PG, et al. An evidence map of the effect of tai chi on health outcomes. Syst Rev. 2016;5:126.

25. Li F, Harmer P, Liu Y, et al. A randomized controlled trial of patient-reported outcomes with tai chi exercise in Parkinson's disease. Mov Disord. 2014;29(4):539-545.

26. Howell RT. A Brief History of Tai Chi [essay]. Golden Lion Academy wesbite. http:// www.goldenlion.com.au/tai-chi/history-tai-chi/. Published 2003. Accessed September 20, 2017.

27. Jesse DE, Reed PG. Effects of spirituality and psychosocial well-being on health risk behaviors in Appalachian pregnant women. J Obstet Gynecol Neonatal Nurs. 2004;33(6):739-747.

28. Reed PG. Spirituality and well-being in terminally ill hospitalized adults. Res Nurs Health. 1987;10(5):335-344.

29. Raes F, Pommier E, Neff KD, Van Gucht D. Construction and factorial validation of a short form of the Self-Compassion Scale. Clin Psychol Psychother. 2011;18(3):250-255.

30. Dailey DE, Stewart AL. Psychometric characteristics of the spiritual perspective scale in pregnant African-American women. Res Nurs Health. 2007;30(1):61-71.

31. Auer S, Graessel E, Viereck| C, Kienberger U, Span E, Luttenberger K. Professional care team burden (PCTB) scale - reliability, validity and factor analysis. Health Qual Life Outcomes. 2015;13:17.

32. Diener E, Wirtz D, Tov W, et al. New well-being measures: short scales to assess flourishing and positive and negative feelings. Soc Indicators Res. 2010;97(2):143156.

33. Silva AJ, Caetano A. Validation of the flourishing scale and scale of positive and negative experience in Portugal. Soc Indicators Res. 2013;110(2):469-478.

34. Li F, Bai X, Wang Y. The scale of positive and negative experience (SPANE): psychometric properties and normative data in a large Chinese sample. PLOS One. 2013;8(4):e61137.

35. Schwarzer R, Jerusalem M. Generalized self-efficacy scale. In: Weinman J, Wright $\mathrm{S}$, Johnston M. Measures in Health Psychology: A User's Portfolio. Causal and control beliefs. Windsor, UK: NFER-NELSON; 1995;35-37.

36. Fredrickson BL, Cohn MA, Coffey KA, Pek J, Finkel SM. Open hearts build lives: positive emotions, induced through loving-kindness meditation, build consequential personal resources. J Pers Soc Psychol. 2008;95(5):1045-1062.

37. Davidson RJ, Kabat-Zinn J, Schumacher J, et al. Alterations in brain and immune function produced by mindfulness meditation. Psychosom Med. 2003;65(4):564-570.

38. Carson JW, Keefe FJ, Lynch TR, et al. Loving-kindness meditation for chronic low back pain: results from a pilot trial. J Holist Nurs. 2005;23(3):287-304.

39. Cheng C. Cheng Tzu's Thirteen Treatises on T'ai Chi Ch'uan. Berkeley, CA: North Atlantic Books; 1985.

40. Huang A. Tai Ji. Berkeley, CA: Celestial Arts; 1989.

41. Robins JL, Elswick RK, McCain NL. The story of the evolution of a unique tai chi form: origins, philosophy, and research. J Holist Nurs. 2012;30(3):134-146.

42. Scourfield P. The symbolic value of tai chi for older people. Quality in Ageing and Older Adults. 2006;7(2):4-12.

43. Khoo YJ, van Schaik P, McKenna J. The Happy Antics programme: holistic exercise for people with dementia. J Bodyw Mov Ther. 2014;18(4):553-558.

44. Davidson RJ, Lutz A. Buddha's brain: neuroplasticity and meditation. IEEE Signal Process Mag. 2008;25(1):176-174. 